\title{
The Synthesis of Diaminoanthraquinone Coloured Cross Linked Epoxy Resins and Their Application in Paint and Selected Polymers
}

\author{
Zwahruddeen Muhammad Salisu' ${ }^{1}$, Mohammed Kabir Yakubu ${ }^{2 *}$, \\ Peter Obinna Nkeonye ${ }^{2}$, Hamza Abba $^{3}$ \\ ${ }^{1}$ National Research Institute for Chemical Technology (NARICT), Zaria, Nigeria \\ ${ }^{2}$ Department of Textile Science and Technology, Ahmadu Bello University, Zaria, Nigeria \\ ${ }^{3}$ Department of Chemistry, Ahmadu Bello University, Zaria, Nigeria \\ Email: kkoko80001@yahoo.com
}

Received 1 October 2013; revised 9 November 2013; accepted 20 November 2013

Copyright (c) 2014 Zwahruddeen Muhammad Salisu et al. This is an open access article distributed under the Creative Commons Attribution License, which permits unrestricted use, distribution, and reproduction in any medium, provided the original work is properly cited. In accordance of the Creative Commons Attribution License all Copyrights (C) 2014 are reserved for SCIRP and the owner of the intellectual property Zwahruddeen Muhammad Salisu et al. All Copyright (C) 2014 are guarded by law and by SCIRP as a guardian.

\section{Abstract}

Novel polymeric pigments were synthesized in xylene by cross linked epoxy resin with 1,4 and 1,5-diaminoanthraquinones, by varying weight fractions from $5 \%$ to $20 \%$ of the diaminoanthraquinone derivatives. FTIR, UV and solubility tests were carried out. The pigments were then used to colour PLA, PMMA, PE and also in emulsion paints using polyvinyl alcohol as binder. Their light fastness, surface drying time and surface hardening time were assessed. It was found that $\lambda_{\max }$ of the 1,4-diaminoanthraquinone shifted towards longer wavelength after the cross linkage, in contrast to the 1,5-diaminoanthraquinone which suffered a blue shift. However in all the cases, the $\lambda_{\max }$ was not affected by the weight fractions of the anthraquinones, but the absorptivity coefficients was significantly increased as the weight fractions of the anthraquinones increased. The light fastness properties of the coloured plastics varied from 4 to 7 , indicating a trend of increase with the weight fractions of the anthraquinones. Similar observations were seen with the emulsion paints produced. In all the cases, the 1,4-diaminoanthraqunione produced better result.

\section{Keywords}

Epoxy Resin; Diaminoanthraquinone Derivatives; Chromophore; Pigments

\footnotetext{
"Corresponding author.
} 


\section{Introduction}

Polymeric dyes are produced by incorporating a chromophoric group into a polymer [1], and they have been synthesized with their new areas of applications continuously being explored over the last three decades. Their strongest advantages over the monomeric counterparts are being non-subliming, non-abrasive and generally with low toxicity [2]. All of these properties are consequents of their high molecular size and invariably strong inter and intra forces of attractions. They have been used as textile dyes due to excellent performance properties such as leveling, fastness to light and wet treatments, and very good thermal and chemical resistance. They also impart very bright colours [3-5]. Other outlets for these dyes are in food coloration, surface coatings, hair dyes [6], solid state laser dyes [7], and jet printing [8,9]. Polymeric colorants offer the advantage of allowing tunability in a range of physical properties such as solubility, absorption, migration, and viscosity.

Among the several efforts made in their synthesis, polyurethanes and polystyrene based colorants have been reported many years ago [10-12]. A very interesting study was conducted by Patel, et al. (2004) who synthesized colored polyureas using a polycondensation reaction of azo disperse dyes containing free amino groups with 4,4-diphenyl diisocyanate. They showed that the dyes had very good thermal properties and were insoluble in many common solvents [13]. We also reported the synthesis and some characteristics of the polycondensation products of polyamides of diaminoanthraquinone [14]. Other inspiring studies include the synthesis and light emitting properties of polymeric metal complex dyes based on hydroxyquinoline moiety [15], polymeric dyes for photovoltaic applications [16], and synthesis of novel water soluble cross-linked polymeric dyes with good dyeing properties $[2,17]$.

There have been several reports of the use of crosslinking agents in the synthesis and application of polymeric dyes. Polyallylamine was reacted with 2,4-dinitrochlorobenzene to produce a dye which could be attached to substrates by crosslinking with 1,3,5-s-triazine substituents [18]. Protein macromolecule could also be dyed with reactive dyes and fixed onto protein fibres with crosslinking agents [19].

Epoxy resins have been used for several years in the manufacture of high performance coatings and paints [20]. Epoxy resins are cured by the use of crosslinking agents, most of which are polyamino compounds.

It is with this belief in mind that we attempt the synthesis of coloured epoxy resins and explore their application for the coloration of plastics and use as pigments in emulsion paint formulation. To the best of our knowledge and extensive literature search, this is the first attempt of this nature.

\section{Materials and Methods}

\subsection{Synthesis of Polymeric Dyes/Pigments}

The synthesis of the pigments was done by a step growth condensation polymerization of specified ratio of 1,4-diaminoanthraquinone (1,4-DAQ), 1,5-diaminoanthraquinone (1,5-DAQ) and Poly(Bisphenol A-co-epichlorohydrin(EPCH) as summarized in Table 1.

The requisite quantity of the epoxy (EPCH), $6.25 \mathrm{~g}$; was dissolved in $5 \mathrm{ml}$ xylene and added to the calculated amount of the anthraquinone also in $5 \mathrm{ml}$ xylene drop wise for 15 minutes. After a homogenous solution was obtained, $5 \mathrm{ml}$ of xylene was added with constant stirring with a mechanical shaker. The mixture was then warmed to $60^{\circ} \mathrm{C}$ in a water bath and maintained for $2 \mathrm{hrs}$. The temperature was raised to $80^{\circ} \mathrm{C}$ and maintained for another $2 \mathrm{hrs}$, then poured into a beaker and placed in an oven set at $120^{\circ} \mathrm{C}$ for $4 \mathrm{hrs}$. Different ratios of the epoxy resin to the diaminoanthraquinone were used, $5 \%$ to $20 \%$ weight fractions at $5 \%$ intervals as shown in Table 1. A portion of $50 \mathrm{mls}$, Sodium carbonate solution (1\%) was used for solvent extraction to purify the pigment until the aqueous layer was colourless.

Table 1. The formulation recipe for the polymeric dyes.

\begin{tabular}{ccccc}
\multicolumn{2}{c}{ Quantity of EPCH } & \multicolumn{2}{c}{ Quantity of 1,4 and 1,5-DAQ } & Pigment Code Number \\
Mass (g) & \%Weight Fraction & Mass(g) & \%Weight Fraction & P \\
6.25 & 95 & 0.33 & 10 & 15 \\
6.25 & 90 & 0.70 & 20 & P10 \\
6.25 & 85 & 1.11 & P15 \\
6.25 & 80 & 1.57 & P20 \\
\hline
\end{tabular}




\subsection{UV-Vis Spectroscopy of Pigments}

Visible absorption spectra of the pigments were measured using Colorimeter 253 spectrophotometer. Xylene was used as solvent. The results obtained were summarized in Table 2.

\subsection{Solubility Test}

The solubility test was carried out by using common laboratory solvents (chloroform, tetrahydrofuran and xylene) at room temperature $\left(25^{\circ} \mathrm{C}\right)$. A small amount of the pigment was placed in a watch glass and the solvent added with continuous stirring with a glass rod for over 3 minutes, the solubility was indicated when one layer was obtained. The results are shown in Table 3.

\subsection{R Spectroscopy}

The samples were characterized using $\mathrm{KBr}$ disc sampling method. The disks were prepared by grinding the sample (2\% by weight) in $\mathrm{KBr}$ which was then compressed into a disk and analyzed with the spectrophotometer. All the spectra were recorded over the range $4000-400 \mathrm{~cm}^{-1}$.

\subsection{Application of the Synthesised Polymeric dyes/Pigment on Some Polymers}

The synthesised pigments were applied to PMMA; (Polymethylmethaacrylate); and PLA; (Polylactic acid) by solution casting in xylene and unto PE; (Polyethene), by melt casting at $120^{\circ} \mathrm{C}$.

\subsection{Paint Formulation}

Polyvinyl acetate (PVAc); $150 \mathrm{~g}$, was dissolved in ethanol; $750 \mathrm{ml}$, at room temperature for 5 hours with

Table 2. The UV-visible spectrophotometer data.

\begin{tabular}{ccccc}
\hline PIGMENT & $\lambda(\mathbf{n m})_{\max }$ & A unit & $a_{1 \mathrm{~cm}}^{1 \%}$ & $\varepsilon\left(\mathrm{lmol}^{-1} \cdot \mathrm{cm}^{-1}\right)$ \\
\hline PURE(1,4) & $\mathbf{5 2 0}$ & 1.000 & 100 & 238.00 \\
4P5 & $\mathbf{5 8 5}$ & 0.543 & 54.3 & - \\
4P10 & $\mathbf{5 8 5}$ & 0.577 & 57.7 & - \\
4P15 & $\mathbf{5 8 5}$ & 0.674 & 67.40 & - \\
4P20 & $\mathbf{5 8 5}$ & 0.897 & 89.70 & - \\
PURE(1,5) & $\mathbf{4 9 5}$ & 0.897 & 89 & - \\
5P5 & $\mathbf{4 8 0}$ & 0.321 & 32.10 & - \\
5P10 & $\mathbf{4 8 0}$ & 0.459 & 45.90 & - \\
5P15 & $\mathbf{4 8 0}$ & 0.464 & 46.40 & - \\
5P20 & $\mathbf{4 8 0}$ & 0.615 & 61.50 & \\
\hline
\end{tabular}

Key: 4P means the 1,4-Anthraquinone dye, 5P stands for the 1,5-Anthraquinone dye; 4P5...20 and 5P5...20, represent the weight fractions of the respective dyes in the pigments.

Table 3. The solubility behavior of the pigments.

\begin{tabular}{cccc}
\hline Sample & Acetone & Tetrahydrofuran & \multicolumn{1}{c}{ Xylene } \\
$\mathbf{4 P 5}$ & Soluble & Soluble & Very Soluble \\
$\mathbf{4 P 1 0}$ & Soluble & Fairly Soluble & Very Soluble \\
$\mathbf{4 P 1 5}$ & Slightly Soluble & Fairly Soluble & Soluble \\
$\mathbf{4 P 2 0}$ & Slightly Soluble & Slightly Soluble & Sery Soluble \\
$\mathbf{5 P 5}$ & Very Soluble & Soluble & Very Soluble \\
$\mathbf{5 P 1 0}$ & Very Soluble & Fairly Soluble & Very Soluble \\
$\mathbf{5 P 2 0}$ & Soluble & Slightly Soluble & Soluble
\end{tabular}


constant stirring to obtain a homogenous solution. From this stock solution of PVAc, $5 \mathrm{ml}$ was mixed with ammonia (0.02 ml), formaldehyde $(0.1 \mathrm{ml})$, kaolin $(0.2 \mathrm{~g}), \mathrm{CaCO}_{3}(0.2 \mathrm{~g})$ and pigment $(0.33 \mathrm{~g})$ and stirred for an hour at $35^{\circ} \mathrm{C}$. Grinding of pigment/mixing of paint was achieved using a ceramic pestle and mortar. The mixture was mulled and stirred vigorously for 1 hour. The resultant paint was poured into a clean and air tight container for further characterization [21].

\subsection{Application of Paints to Substrate}

The paints were applied on a particle ceiling board popularly known as Duratex, a Brazil ceiling board acquired from Samaru Market, Zaria, Nigeria. The samples each measuring $150 \mathrm{~mm} \times 30 \mathrm{~mm}$ were cut and ensured to be clean, dry and free from imperfections. One inch (1") Chuto bristle hand brush was used for the application of the paints. Four (4) coated samples were produced from the corresponding four (4) paints formulated plus one (1) market sample (control).

\subsection{Light Fastness}

The pigmented polymers, were prepared for the light fastness test by compressing the polymers in a compression moulding machine in NILEST Samaru, Zaria. The conditions for the compression are $150^{\circ} \mathrm{C}$ and $5 \times 10^{6} \mathrm{~kg}$ for 4 minutes respectively. Light fastness test of the painted samples was carried out by the use of direct sunlight for a period of 45 days. The procedure involved aligning both the eight AATCC Blue Wool Light fastness Standards together with the painted specimen on a cardboard. 2/3 of both the wool standards and the samples were covered with opaque cardboard while the rest was exposed to direct sunlight. Exposure was carried out until the last specimen to fade had faded to the extent of standard three of the standard AATCC Gray Scale for Color Change for evaluating change in colour. The rating of the painted sample is that of the wool dyed sample, which faded to the same extent as the sample at the same time. The results are shown in Table 4.

\subsection{Surface Drying Time}

This measures the relative degree of cure (dry to touch). It was measured by the quantitative finger marking test. The time taken for a coated sample to dry was measured by sporadically touching the coating with small white paper until there was no stain noticed on the paper. The experiment was repeated for the other three samples while the commercial paint served as control. The results are shown in Table 5.

\subsection{Hard Drying Time}

This was the time taken for the coated sample to be completely dried and could withstand or resist gentle scratch. The hard drying times for all samples were recorded and compared with the commercial paint. The results are shown in Table 5.

\begin{tabular}{ccccc} 
Table 4. The light fastness result of the pigments in the Polymers and Paint. & & \\
\hline PIGMENT & PLA & PE & PMMA & PAINT \\
\hline 4P5 & 5 & 5 & 4 & 6 \\
4 P10 & 6 & 5 & 4 & 5 \\
4 P15 & 6 & 6 & 7 & 6 \\
4P20 & 7 & 7 & 4 & 5 \\
5P5 & 5 & 5 & 4 & 5 \\
5P10 & 6 & 5 & 5 & 6 \\
5P15 & 6 & 6 & 6 & 6 \\
5P20 & 7 & 6 & - & 5 \\
SHARON & - & - & 5
\end{tabular}

Key: 8 is excellent, 7 is very good ... 1 is very poor in that order. 
Table 5. Surface Drying and hardening time.

\begin{tabular}{ccc}
\hline Pigments of Paint & Surface Drying Time (Seconds) & Surface Hardening Time (Seconds) \\
\hline 4P5 & 45 & 90 \\
4P10 & 48 & 87 \\
4P15 & 54 & 83 \\
4P20 & 49 & 69 \\
5P5 & 43 & 80 \\
5P10 & 47 & 83 \\
5P15 & 52 & 86 \\
5P20 & 50 & 70 \\
\hline
\end{tabular}

\section{Results and Discussion}

\subsection{UV-Visible Interpretation}

The UV spectra of the pigments derived from 1,4-DAQ dissolved in xylene generally indicated a bathochromic shift of around $65 \mathrm{~nm}$. The $\lambda_{\max }$ of the 1,4-DAQ was $520 \mathrm{~nm}$ compared to the epoxidized ones which recorded $585 \mathrm{~nm}$. The variation in the ratio of the anthraquinone to the epoxy didn't cause any change in $\lambda_{\max }$. However, the absorptivity coefficients of the pigments did show a trend of increase with the ratio of the anthraquinone to the epoxy. The pigments were in the bluish-red range and their absorption varied with the concentrations. It also showed that those obtained from 1,5-DAQ had their $\lambda_{\max }$ at $480 \mathrm{~nm}$ (after cross linking with epoxy) whilst pure 1,5-DAQ had $\lambda_{\max } 495 \mathrm{~nm}$, a hypsochromic shift of about $15 \mathrm{~nm}$. Their absorptions were as in Table 2. Figure 1 showed that the difference in the absorption coefficient of the 1,4-DAQ between $100 \%$ and $20 \%$ weight fractions was less compared to the 1,5-DAQ.

While explaining the UV-Vis spectra of 1,4-anthraquinone embedded in Polyurathane, Hu, et al., (2004) assigned the observed three absorptions at 555, 600 and $650 \mathrm{~nm}$, to $\mathrm{n} \rightarrow \sigma *, \pi \rightarrow \pi *$ and $\mathrm{n} \rightarrow \pi *$ electronic transitions respectively. The absorption peak weakened with the decrease of molecular weight of aqueous dispersions.

From the results obtained it showed that pigments made from 1,4-DAQ recorded higher absorbtivity coefficients compared to 1,5-DAQ pigments. The one with the higher concentration of 1,4-DAQ cross linked epoxy resin was the best of all. This could be due to the planarity nature of 1,4-DAQ compared to the 1,5-DAQ as shown in Schemes 1 and 2.

\subsection{IR Interpretation}

FTIR spectroscopy was used to characterize the structure of pure epoxy resin and the modified epoxy resins. Some of the FTIR spectra are shown in Figure 2. For pure epoxy resin, the band at $3500 \mathrm{~cm}^{-1}$ is assigned to -OH stretching. The bands at 2965 and $1383 \mathrm{~cm}^{-1}$ are characteristic of $-\mathrm{CH}_{3}$ asymmetric and symmetric stretching, and the bands at 2877 and $1457 \mathrm{~cm}^{-1}$ are assigned to asymmetric and symmetric stretching mode of $-\mathrm{CH}_{2}$. The band at $915 \mathrm{~cm}^{-1}$ is the characteristic absorption of epoxide groups. The band at $1235 \mathrm{~cm}^{-1}$ is assigned to the ether bonds in epoxide groups. The absorption peaks at 1607, 1508 and $828 \mathrm{~cm}^{-1}$ are characteristics of substituted aromatic rings in epoxy resin.

The fundamental reaction of concern in this analysis involved the condensation of the amine functional group $-\mathrm{NH}_{2}$ in the diaminoanthraquinone with the epoxy resin to form the pigments. The aromatic ring benzene bands is weak compared to $\mathrm{C}=\mathrm{C}$ in aliphatic systems. Hexa-substituted $3030 \mathrm{~cm}^{-1}$ aromatic stretching, $1613-1471$ $\mathrm{cm}^{-1}$ ring skeletal vibration, $\mathrm{C}=\mathrm{C}$ - strong peak at $1461 \mathrm{~cm}^{-1}$ [22-24]. All the compounds indicated -NH absorption bands at $2500-3600 \mathrm{~cm}^{-1}$ and absorptions around $1630-1680 \mathrm{~cm}^{-1}$ could be attributed to $-\mathrm{C}=\mathrm{N}$ bonds [25] which could indicate some sought of tautomerism with the transfer of a proton from the NH group to the carbonyl oxygen on the anthraquinone. The $1630-1680 \mathrm{~cm}^{-1}$ could also be attributed to intra-molecular hydrogen bonds [26].

\subsection{Solubility Test of Synthesized Pigments}

The solubility of the pigments was tested using some common laboratory solvents such as acetone, tetraoxohy- 


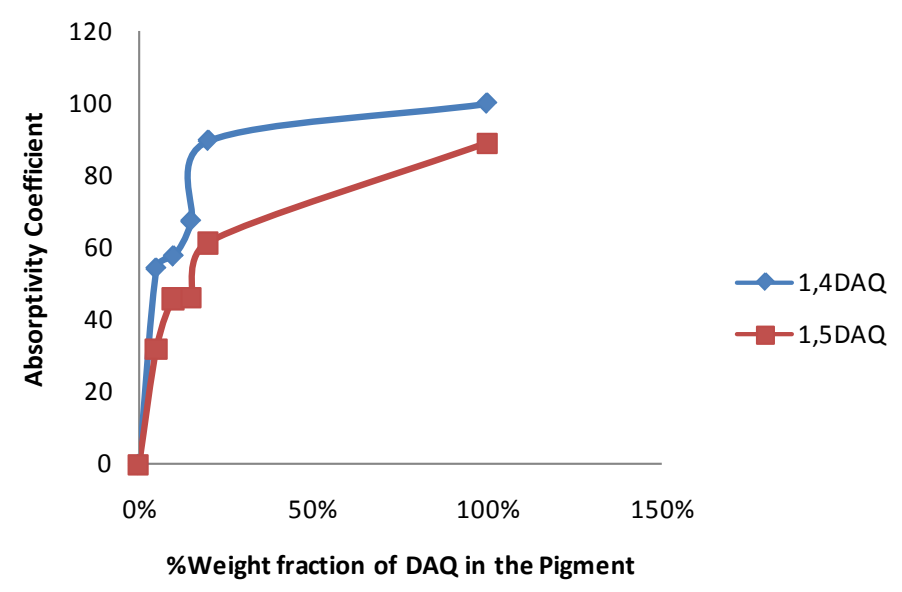

Figure 1 . The absorptivity coefficient $\left(\alpha_{1 \mathrm{~cm}}^{1 \%}\right)$ of the pigment with varying \%weight fraction of DAQ.<smiles>CC(COc1ccc(C(C)(C)c2ccc(OCC(O)CO)cc2)cc1)c1ccccc1</smiles><smiles>CCOc1ccc(C(C)(C)c2ccc(OCC(O)CO)cc2)cc1</smiles>

Scheme 1. Mechanism of reaction between the epoxy resin and the 1,4-diaminoanthraquinone pigment.

drofuran and xylene. The results are as in Table 3.

Table 3 shows that the pigments were more soluble in xylene than any of the three solvents tested. The order of decreasing solubility is xylene, tetrahydrofuran, acetone.

\subsection{Light Fastness Results}

Table 4, shows the pigments obtained from (1,4)-diaminoAQ are more compatible with the polymers (PE, PLA, PMMA). This could be due to the fact that $(1,4)$-diaminoAQ is more asymmetrical leading to its shielding effect from the UV-rays, while (1,5)-diaminoAQ is less. This is reflected in the light fastness test results which showed 
<smiles>CC(CO)(CO)COc1ccc(C(C)(C)c2ccc(OCC3CO3)cc2)cc1</smiles><smiles>CC(O)COc1ccc(C(C)(C)c2ccc(OCC(C)O)cc2)cc1</smiles>

Scheme 2. Mechanism of reaction between the epoxy resin and 1,5-diaminoanthraquinone pigment.

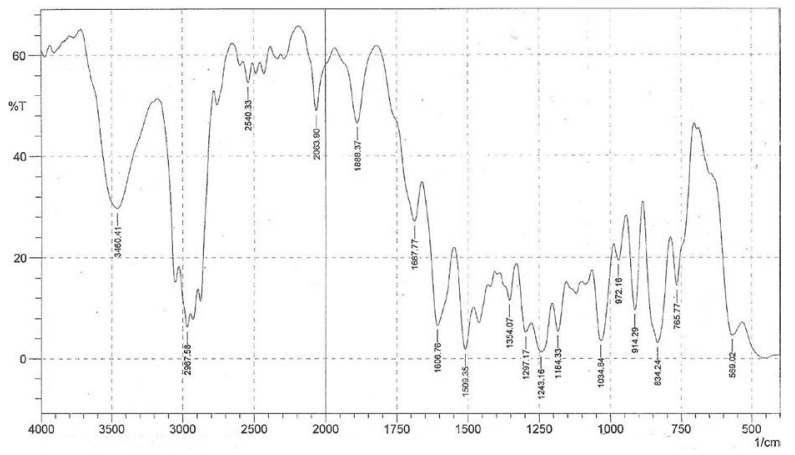

(a) 1,4-diaminoanthraquinone

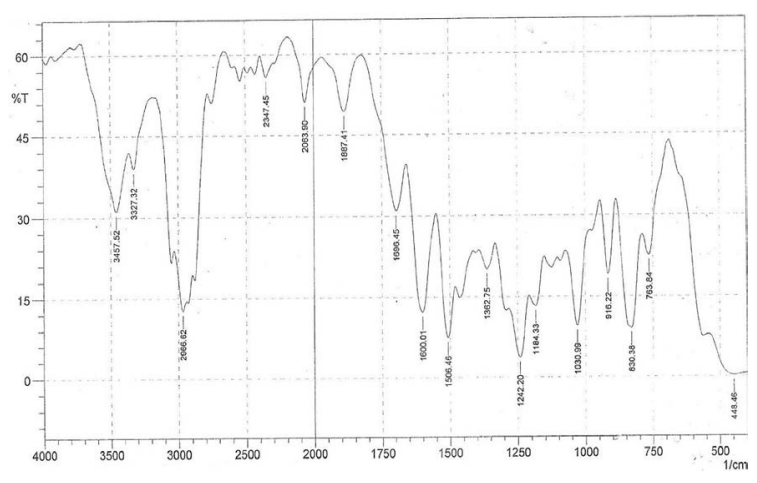

(c) 1,5-diaminoanthraquinone

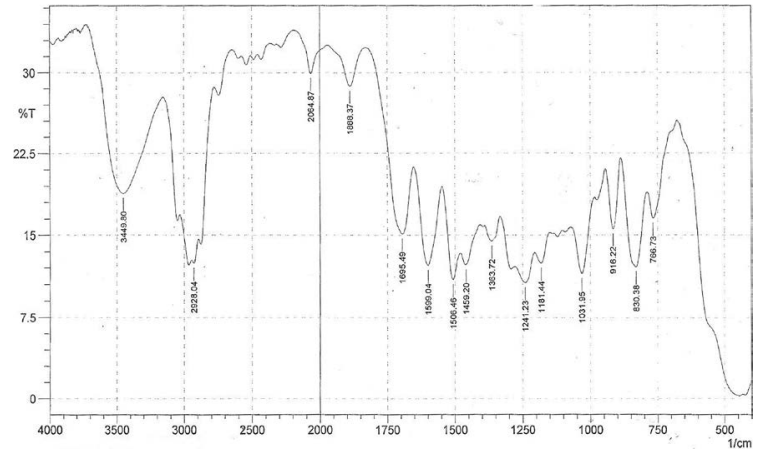

(b) $4 \mathrm{P} 20$

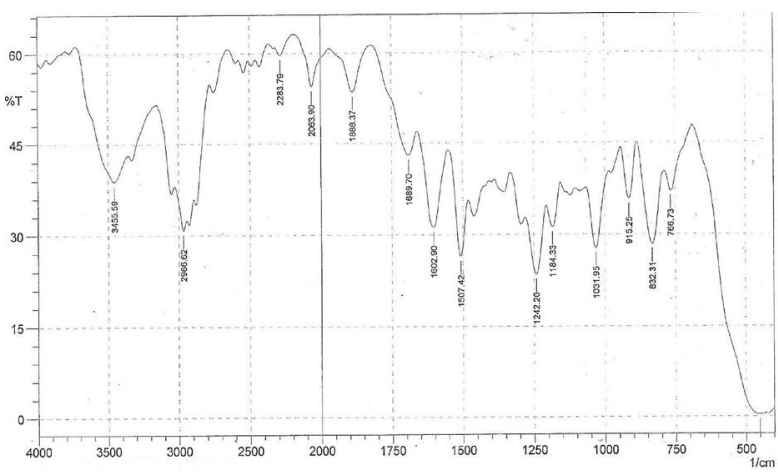

(d) 5 P15

Figure 2. The IR Spectra of some of the pigments. 
1,4-diaminoAQ pigments to have higher light fastness than those obtained from 1,5-diaminoAQ.

\subsection{Paint Surface Drying Time/Paint Surface Hardening Time}

Table 4, gave the surface drying and hardening times of the paints. The paints from the pigments have good and short surface drying time and surface hardening time though this is also the effect of the pigment molecular weight. The surface drying and hardening time is increasing in the sequence of degree of $\mathrm{H}$-atom substitution by the epoxy resins in the anthraquinones derivatives.

\section{Conclusion}

This work has shown that organic pigments can be synthesised by reacting epoxy resin with coloured diaminoanthraquinones. In this study, 1,4-diaminoanthraquinone and 1,5-diaminoanthraquinone were used. The coloured resins depicted hues not much different from the diaminoanthraquinone precursors. The pigments were produced with varying weight fractions, and the result showed that the absorptivity coefficient of the $20 \%$ weight fraction was more than $80 \%$ of the original diaminoanthraquinone. The preliminary assessments of the pigments as colorants for some thermoplastics and in paints showed some good promise. Generally speaking the light fastness result was good to very good. The 1,4-anthraquinone produced pigments with better result than the 1,5-anthraquinone did.

\section{References}

[1] Libert, C. and Marechal, E. (1980) Synthesis of macromolecules containing colour forming monomers. European Polymer Journal, 16, 951-956. http://dx.doi.org/10.1016/0014-3057(80)90176-7

[2] Joshi, M., Jauhari, S. and Desai, K. (2011) Polyureas: Synthesis and characterization. International Journal of ChemTech Research CODEN (USA), 3, 29-32.

[3] Maradiya, H. and Patel, V. (2002) Studies of novel nonnumeric and polymeric Azo disperse dyes. Journal of Applied Polymer Science, 84, 1380-1389. http://dx.doi.org/10.1002/app.10276

[4] Hu, X., Zhang, X., Dai, J. and Xu, G. (2004) Synthesis and characterization of a novel aqueous dispersion poly[urethane-(disperse blue 14) urethane] dye. Chinese Chemical Letters, 15, 515-517.

[5] Maradiya, H. and Patel, V. (2003) N-arylmaleimide based monomeric and polymeric dyes for cellulose triacetate fibric. International Journal of Polymeric Materials, 52, 119-131. http://dx.doi.org/10.1080/714975923

[6] Shah, K., Patel, M., Amin, K., Patel, R. and Patel, V. (1997) ActaCienc India Chem, 23, 177.

[7] Tian, M., Hawkins, G. and Chan, A. (2003) United States of America Patent US 2003106168.

[8] Wang, J., Chen, H. and Evans, S. (2003) Europe Patent EP1283249.

[9] Parrinello, L., Rogers, R., Hill, C., Lipko, L.E., Benenati, P. and Nowakowski, P. (2003) United States of America Patent USP 2003180523.

[10] Singh, K., Singh, S. and Taylor, J.A. (2002) Monoazo disperse dyes-Part 1: Synthesis, spectroscopic studies and technical evaluation of Monoazo disperse dyes derived from 2-aminothiazoles. Dyes and Pigments, 54, 189-200. http://dx.doi.org/10.1016/S0143-7208(02)00053-0

[11] Konstantinova, T., Meallier, P., Konstantinova, H. and Staneva, D. (1995) Synthesis and photochemical properties of triazinyaminobenzanthrone derivatives as dyes for polymeric material. Polymer Degradation and Stability, 48, 161165. http://dx.doi.org/10.1016/0141-3910(95)00014-D

[12] Meng, Q.H., Huang, D.Y., Wei, S.H. and Chen, L. (2002) Synthesis and application of polymeric dyes containing the anthraquinone structure. Journal of Applied Polymer Science, 83, 1252-1257.

[13] Patel, M., Desai, K. and Patel, H. (2004) Synthesis and characterisation of colored polyureas. E-Journal of Chemistry, 1, 51-56. http://dx.doi.org/10.1155/2004/812751

[14] Gumel, S., Yakubu, M., Ibrahim, M. and Kumar, R. (2012) Synthesis and characterization of colourants derived from 1,4-diamino anthraquinone polymides. Advances in Chemical Engineering and Science, 2, 200-308.

[15] Kim, S.-H., Cui, J.-Z., Park, J.-Y., Ryu, J.-H., Han, E.-M., Park, S.-M., Jin, S.-H., Koh, K. and Gal, Y.-S. (2002) Synthesis and light emitting properties of polymeric metal complex dyes based on hydroxyquinoline moiety. Dyes and Pigment, 55, 91-97. http://dx.doi.org/10.1016/S0143-7208(02)00088-8

[16] Fernando, J.M.R. and Sanadeera, G. (2008) Synthesis and characterization of carboxylatedthiophene co-polymers and 
their use in photovoltaic cells. Current Science, 95, 743-750.

[17] Park, J., Yang, J., Lee, J., Lim, E., Suh, J., Huh, Y. and Haan, S. (2009) Synthesis and characterisation of florescent magneto polymeric nanoparticles (FMPNs) for bimodal imaging probe. Journal of Colloid and Interface Science, 340, 1252-1257. http://dx.doi.org/10.1016/j.jcis.2009.08.015

[18] Tang, B., Zhang, S., Yang, J. and Liu, F. (2006) Synthesis of a novel water soluble crosslinking polymeric dye with good dyeing properties. Dyes and Pigments, 68, 69-71. http://dx.doi.org/10.1016/j.dyepig.2004.11.005

[19] Zhang, S. and Yang, J. (1997) Protein macromolecule dye. China Patent 97112231.

[20] Krysin, A.P. and Yakovlev, O. (2013) Fabrication of coatings based on epoxy resins for environmental protection of microelectronics. Russian Journal of Applied Chemistry, 86, 997-1000. http://dx.doi.org/10.1134/S1070427213070094

[21] Method for Testing Pigments for Paints. (1962) British Standard House, London, 10-15.

[22] Ogugbujuaja, V. (2010) Absorption/emission spectroscopy: An instrumental methodology in analytical chemistry. 3rd Edition, El-Elyon Digital Publishing House, Kaduna.

[23] Solomons, G.T.W. (2011) Organic chemistry. 10th Edition, John Wiley and Sons Inc., Hoboken.

[24] Ahmad, Y. (2012) A practical guide to instrumental analysis a review. NARICT, Basawa Zaria.

[25] Verma, B. and Parmer, M.S. (1994) NMR and IR studies of some metal complexes of 6-substituted-1-hydroxy1,2,3-benzotrizoles. Asian Journal of Chemistry, 6, 22-25.

[26] Reddy, D., Reddy, N., Sridhar, V. and Rayana, S. (2002) Coenzyme B12 model studies: Equilibrium constants for the $\mathrm{pH}$ dependent axial ligation of benzyl(aquo) cobaloxime by various $\mathrm{N}$ and S-donor ligands. Journal of Chemical Sciences, 114, 1-10. 